\title{
TABLE DES ARTICLES
}

COnTENus Dans Les

\section{VINGT PREMIÉRES ANNÉES}

DE LA

\section{REVUE INTERNATIONALE}

DB LA

\section{CROIX-ROUGE 1919-1938}

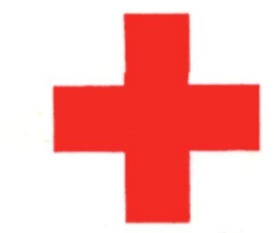

INTER ARMA CARITAS

GENEVE

AU SIÈGE DU COMITE INTERNATIONAL DE LA CROIX-ROUGE 122, rue de Lausanne

JANVIER 1939 


\section{TABLE DES ARTICLES}

CONTENUS DaNS LES

\section{. VINGT PRE MIÉRES ANNÉES}

DE LA

\section{REVUE INTERNATIONALE DE LA CROIX-ROUGE \\ 1919-1938}




\title{
TABLE DES ARTICLES
}

CONTENUS DANS LES

\section{VINGT PREMIÈRES ANNÉES}

\author{
DE LA \\ REVUE INTERNATIONALE \\ DE LA \\ CROIX-ROUGE \\ 1919-1938
}

GENÈVE

AU SIÈGE DU COMITÉ INTERNATIONAL DE LA CROIX-ROUGE 122, rue de Lausanne

JANVIER 1939 